\title{
Impacts of using spectral nudging on regional climate model RCA4 simulations of the Arctic
}

\author{
P. Berg, R. Döscher, and T. Koenigk \\ Rossby Centre, Swedish Meteorological and Hydrological Institute, Folkborgsvägen 17, 60176 Norrköping, Sweden \\ Correspondence to: P. Berg (peter.berg@ smhi.se)
}

Received: 17 December 2012 - Published in Geosci. Model Dev. Discuss.: 23 January 2013

Revised: 7 May 2013 - Accepted: 17 May 2013 - Published: 22 June 2013

\begin{abstract}
The performance of the Rossby Centre regional climate model RCA4 is investigated for the Arctic CORDEX (COordinated Regional climate Downscaling EXperiment) region, with an emphasis on its suitability to be coupled to a regional ocean and sea ice model. Large biases in mean sea level pressure (MSLP) are identified, with pronounced too-high pressure centred over the North Pole in summer of over $5 \mathrm{hPa}$, and too-low pressure in winter of a similar magnitude. These lead to biases in the surface winds, which will potentially lead to strong sea ice biases in a future coupled system. The large-scale circulation is believed to be the major reason for the biases, and an implementation of spectral nudging is applied to remedy the problems by constraining the large-scale components of the driving fields within the interior domain. It is found that the spectral nudging generally corrects for the MSLP and wind biases, while not significantly affecting other variables, such as surface radiative components, two-metre temperature and precipitation.
\end{abstract}

\section{Introduction}

The Arctic region is experiencing some of the most dramatic climate change on the planet (Symon et al., 2005; Christensen et al., 2007; Richter-Menge and Jeffries, 2011). Changes in the Arctic climate might have severe consequences for global climate, e.g. through snow and ice cover changes with local and remote effects (Magnusdottir et al., 2004; Alexander et al., 2004; Koenigk et al., 2009; Deser et al., 2010), or the export of freshwater from the Arctic which alters the deep water formation in the North Atlantic (Häkkinen, 1999; Haak et al., 2003; Koenigk et al., 2007).
It is important to gain a deeper understanding of the local processes and atmosphere-cryosphere interactions.

Global Climate Models (GCMs) have shown problems with anomalously high mean sea level pressure (MSLP) values in summer, and with simulating the North Atlantic storm track route into the Arctic region in winter (Chapman and Walsh, 2007; Blanchard-Wrigglesworth et al., 2011). The former causes problems with the near-surface circulation that affects sea ice drift, with resulting distribution biases in sea ice cover and thickness. Improvements in GCMs, especially regarding increased resolution, have been shown to reduce the MSLP biases (Chapman and Walsh, 2007) and improve the spatial distribution of sea ice (DeWeaver and Bitz, 2006).

Regional coupled systems can be used for high-resolution simulations given lateral boundary conditions from a governing global model. However, it has proven difficult to model the Arctic region with regional climate models (RCMs), which often produce circulation errors and other biases (Cassano et al., 2011; Wyser et al., 2008). The main problem is the largely circumpolar circulation which puts large demands on the RCM to produce the correct internal circulation, as little information from the driving model is transferred from the lateral boundaries to the interior domain (Rinke and Dethloff, 2000). With often simplified radiation schemes and limited vertical extent, even RCMs suffer from circulation biases. For a coupled regional atmosphere-ocean system, it is essential to get the surface winds accurately described in order to provide a reasonable sea ice forcing.

Improving the RCM is a long-term task, but efficient methods to constrain the RCM circulation biases are readily available. Here we utilise a method called spectral nudging, which is a method of imposing the larger horizontal scales of the driving GCM data on the interior RCM domain at 
selected atmospheric levels (von Storch et al., 2000). The smaller scales, and especially the lower atmospheric levels of the RCM, are left untouched by the spectral nudging, allowing the RCM to develop its own internal climate under the larger-scale constraints (Alexandru et al., 2009; Šeparović et al., 2012). Initially, the method was a simple alternative for data assimilation, but it has been found to be efficient also in reducing systematic model biases (Laprise et al., 2012). Furthermore, the method has been shown to remove the sensitivity to the RCM domain's size and position (Miguez-Macho et al., 2004).

In the current paper, re-analysis-driven simulations with the RCM RCA4 with and without spectral nudging are investigated. The main purpose is to find a setup suitable for a future coupling to a regional ocean and sea ice model. Therefore, emphasis is on MSLP and surface winds. After presenting the model and observational data used (Sect. 2), tuning simulations of the spectral nudging implementation are presented (Sect. 3). A comparison of a standard simulation to a spectrally nudged one are presented (Sect. 4), followed by discussion and conclusions (Sect. 5).

\section{Data and models}

The Rossby Centre Atmosphere RCM (RCA) is based on the numerical weather prediction model HIRLAM (Undén et al., 2002). An earlier version, RCA3, was described in Samuelsson et al. (2011). However, here RCA4 is used, which is in many respects the same model, but has been re-coded and updated, mostly with respect to surface processes. The current experiments are based on the standard setup of the model for the CORDEX (COordinated Regional climate Downscaling EXperiment) ensemble simulations (see e.g. Table 1 of Nikulin et al. (2012)).

For the current study, spectral nudging was implemented as an optional method for applying boundary conditions to the interior domain. The method and initial tuning experiments are presented in Sect. 3. Common to all simulations is the use of ERA-Interim (Dee et al., 2011) as driving data, and integrations over the period 1979-2005. The domain used is the standard CORDEX-Arctic domain with $150 \times 156$ grid points in a rotated grid at a resolution of 0.44 degrees and 40 vertical model levels (see Fig. 1).

The model integrations are evaluated mainly with the ERA-Interim re-analysis data set. It constitutes a reasonable best guess for the Arctic region, given the general lack of observations. The predecessor of ERA-Interim, i.e. ERA40, has been found accurate for diverse variables over the Arctic (Bromwich et al., 2007). ERA-Interim has been improved regarding the assimilation technique, bias correction of observations, model physics, and resolution, among other things (see Dee et al. (2011)). Additionally, gauge-based gridded data sets from the Climatic Research Unit at the University of East Anglia (Mitchell and Jones, 2005, CRU, version 3.0,

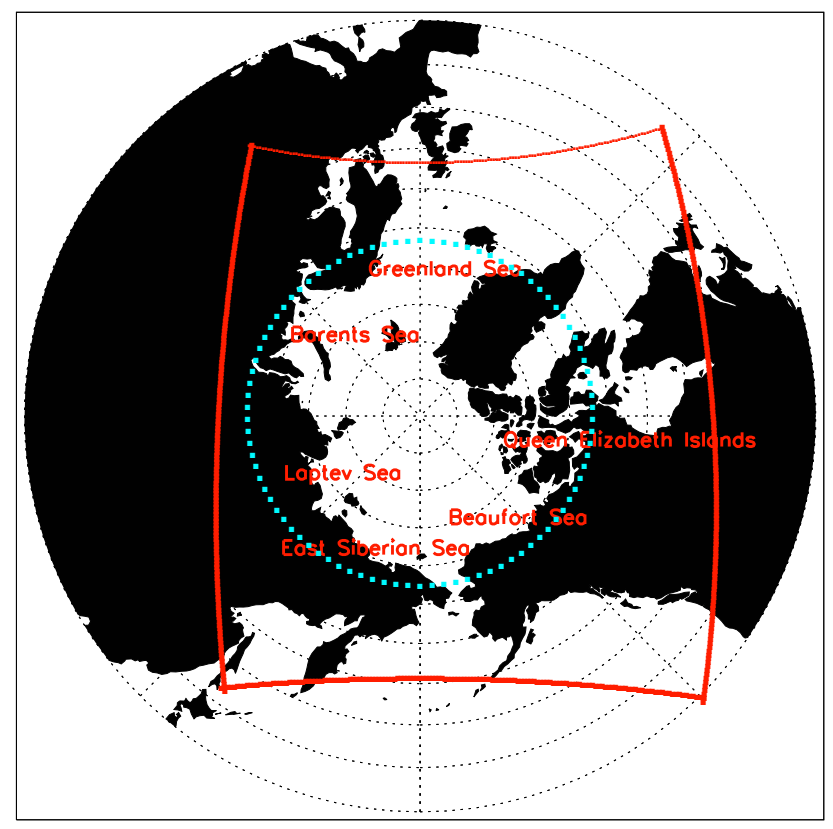

Fig. 1. Simulation domain (unrotated to normal longitude-latitude grid) of the CORDEX-Arctic experiments marked in red. Dashed circles indicate the latitudes in steps of five degrees. The light blue dashed circle indicates $67^{\circ} \mathrm{N}$ latitude, which is the lowest latitude line covered by the full interior domain (ten grid points from the marked domain) of the simulation.

1901-2006) and the University of Delaware (Legates and Willmott, 1990, UDEL, version 2.01, 1901-2008) are used for temperature and precipitation, and also the Global Precipitation Climatology Centre (Rudolf et al., 2010, GPCC, version 5, 1901-2009) is used for precipitation. The time period 1980-2005 was used as the evaluation period.

\section{Spectral nudging}

\subsection{Implementation in RCA4}

The core idea of spectral nudging is that the GCM and RCM should, from a resolution perspective, be equally good at simulating the large-scale motions of the atmosphere, whereas the RCM is expected to outperform the GCM at shorter wavelengths (von Storch et al., 2000). If the RCM does not reproduce the large-scale circulation, the GCM circulation can be imposed on those scales only.

For RCA4, the Denis et al. (2002) method was implemented in a fully parallelisable setup. The method is based on the two-dimensional discrete cosine transform (DCT), which for calculations on the model grid $f(x, y)$ toward the spectral 
Table 1. Tuning parameters for the spectral nudging experiments.

\begin{tabular}{lccc}
\hline Parameter & Abbreviation & Tested values & Explanation \\
\hline Nudging strength & $s$ & $0.1-0.5$ & Strength of the nudging at the top level (1) \\
Nudging frequency & $f$ & $0.25-6 \mathrm{~h}$ & Frequency of the nudging \\
Minimum wavelength & $w$ & $500-2000 \mathrm{~km}$ & Shortest wavelength to nudge \\
Variable & TUV & $t, u$ and $v$ & Which variables to nudge \\
\hline
\end{tabular}

grid $F(u, v)$ is defined as

$$
\begin{gathered}
F(u, v)=\beta(u) \beta(v) \sum_{x=0}^{N-1} \sum_{y=0}^{M-1} f(x, y) \\
\cos \left[\frac{\pi(2 x-1) u}{2 N}\right] \cos \left[\frac{\pi(2 y-1) v}{2 M}\right],
\end{gathered}
$$

and its inverse as

$$
\begin{gathered}
f(x, y)=\sum_{u=0}^{N-1} \sum_{v=0}^{M-1} \beta(u) \beta(v) F(u, v) \\
\cos \left[\frac{\pi(2 x-1) u}{2 N}\right] \cos \left[\frac{\pi(2 y-1) v}{2 M}\right],
\end{gathered}
$$

where $N(M)$ is the number of grid points in the longitudinal (latitudinal) direction, and

$\beta(u)= \begin{cases}\sqrt{\frac{1}{N}} & \text { for } u=0 \\ \sqrt{\frac{2}{N}} & \text { for } u \neq 0\end{cases}$

and similarly for $\beta(v)$. Since RCA4 generally runs on multiple processes, it is more effective to instead apply two consecutive one-dimensional DCTs:

$G(u, y)=\beta(u) \sum_{x=0}^{N-1} f(x, y) \cos \left[\frac{\pi(2 x-1) u}{2 N}\right]$

and

$F(u, v)=\beta(v) \sum_{y=0}^{M-1} G(u, y) \cos \left[\frac{\pi(2 y-1) v}{2 M}\right]$,

and similarly for the inverse. An internal algorithm, inherited from the HIRLAM model (Boerhout, 2003), is used to redistribute the data across the cores so that the necessary complete longitude and latitude rows are achieved. Thus, instead of running subsets of longitude-latitude boxes (on the rotated model grid) with complete vertical columns on the different cores, the domain is split into, e.g., longitude-vertical boxes with complete latitude rows. The one-dimensional DCTs can then be straightforwardly applied, and each calculated in parallel across several cores.

The DCTs are calculated on the difference fields between the driving model data and the RCM data, thus reducing the number of calculations and also the gradients for the treated field (Denis et al., 2002). This can be performed for the typical driving fields of temperature, zonal and meridional winds and specific humidity at all vertical model levels. Note, however, that in practice, and in this paper, only model levels above the planetary boundary layer are nudged.

A filter is constructed such that only a selected range of scales (spectral subsection) are included in the spectral nudging. Typically only an upper limit of the wavelengths is set so that the smaller scales are filtered out, but it is also possible to set a lower limit. The filter is applied after the forward DCTs so that non-relevant spatial scales are filtered out before the inverse DCTs are applied.

Before adding the filtered difference field to the RCM field, it is weighted by a nudging strength factor between 0 and 1 . The factor is a function of the model level, with linearly increasing values from the lowest nudged level to the highest nudged level. Here, a strength of 0.0 is used at the lowest level, and $0.1-0.5$ for the highest level, i.e. the model top.

The nudging can in principle be applied at every time step of the model integration, but to decrease computational cost it is possible to do it at intervals up to the boundary update frequency (here every six hours).

\subsection{Tuning experiments}

The spectral nudging parameters were tuned to give low root mean square error (RMSE) in the $500 \mathrm{hPa}$ geopotential, which is used as an indicator of the large-scale circulation of pressure systems in the domain (Rinke and Dethloff, 2000). Note that the experiments were originally evaluated for the scales that were nudged, but since these differ between several of the simulations, we here show the unfiltered results. The main differences are that RCM-generated smallscale variability is included. Table 1 provides an explanation of the tuning parameters, as well as ranges used for the tuning experiments. Common for all experiments is the use of a lowest-level nudging strength of 0.0 , and a lowest level at model level 30 , i.e. around $850 \mathrm{hPa}$ slightly above the planetary boundary layer.

The tuning simulations are named in accordance with the following format: (1) a letter combination indicating which variables were nudged ( $U$ for zonal wind, $V$ for meridional wind and $T$ for temperature), (2) the nudging strength at the first (topmost) model level indicated with an "s" followed by 

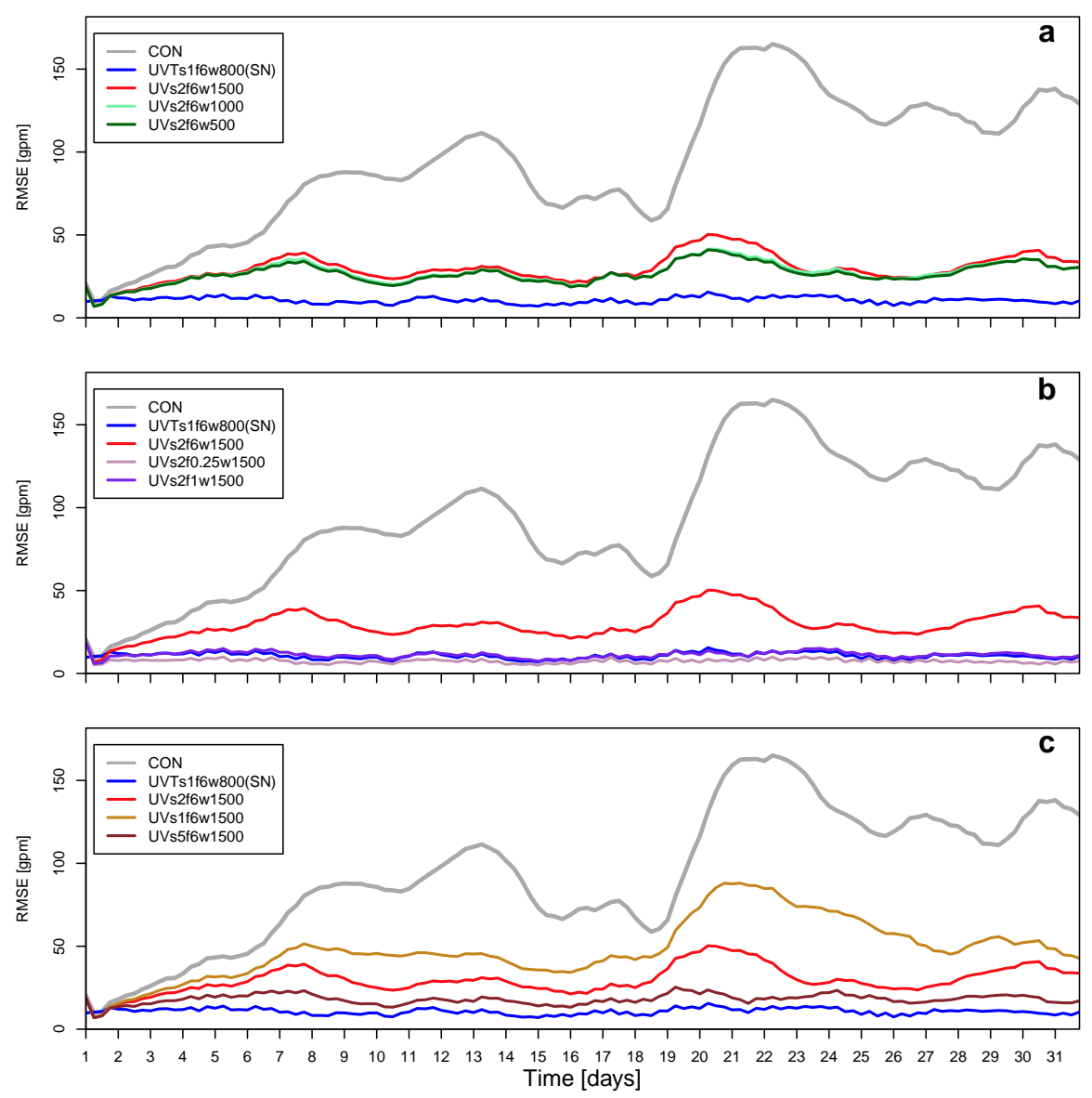

Fig. 2. RMSE of $500 \mathrm{hPa}$ geopotential for different tuning experiments with respect to ERA-Interim. Results are for December 1979, and are shown in steps of six hours. Three sets of experiments are showing sensitivity to (a) the shortest nudged wavelengths, (b) to the calling frequency of the nudging routine, and (c) to the strength of the nudging profile. Simulations are named as explained in the text.

the coefficient multiplied by ten, (3) the nudging frequency indicated with an " $\mathrm{f}$ " followed by the update frequency in unit of hours, and finally (4) the shortest wavelength included in the nudging given in units of $\mathrm{km}$ after the letter "w". For comparison a control simulation without nudging was performed, named "CON". Three stages of tuning were performed: (i) a large set of experiments were carried out for December 1979, which show large deviations between the RCM and the driving model in the interior domain; (ii) a subset of the experiments that performed reasonably well for December were also tested for June 1979; and in a final set of experiments (iii) year-long experiments were performed for the complete year of 1979 . Here, only results for (i) are presented as they are representative also for the other two sets of experiments. A first-guess simulation called UVs $2 \mathrm{f} 1 \mathrm{w} 1500$ was performed as a baseline for the following tuning experiments.

Figure 2 shows results for selected tuning experiments from (i). In each case, the $500 \mathrm{hPa}$ geopotential height RMSE in comparison to the ERA-Interim at time steps of six hours for December 1979 is shown. Common for each of the three panels are the lines showing results for CON (thick grey), the first-guess simulation UVs2f6w1500 (red) and the version used for the simulations investigated in Sect. 4 (UVTs1f6w800; blue).

The deviations from the driving data in the interior domain of CON are clearly seen in the RMSE, most clearly for the latter half of the month. The size of the RMSE is similar to earlier studies with different RCMs (Rinke and Dethloff, 2000; Cassano et al., 2011). The differences between the driving model and the RCM are caused mainly by deep pressure systems that take a different path, or evolve differently with time (not shown). The first-guess simulation UVs2f1w1500 reduces the RMSE significantly, but still deviates from the driving field large-scale circulation at times. Including shorter wavelengths improves the RMSE, but quickly saturates below $1000 \mathrm{~km}$ (see Fig. 2a). This indicates that the main reason for the circulation bias is due to the larger scales. The nudging frequency has a larger impact, and when nudging every one hour, the RMSE is close to stable (see Fig. 2b). Further improvements are possible with, e.g., a 15 min (every timestep) frequency, but the computational 

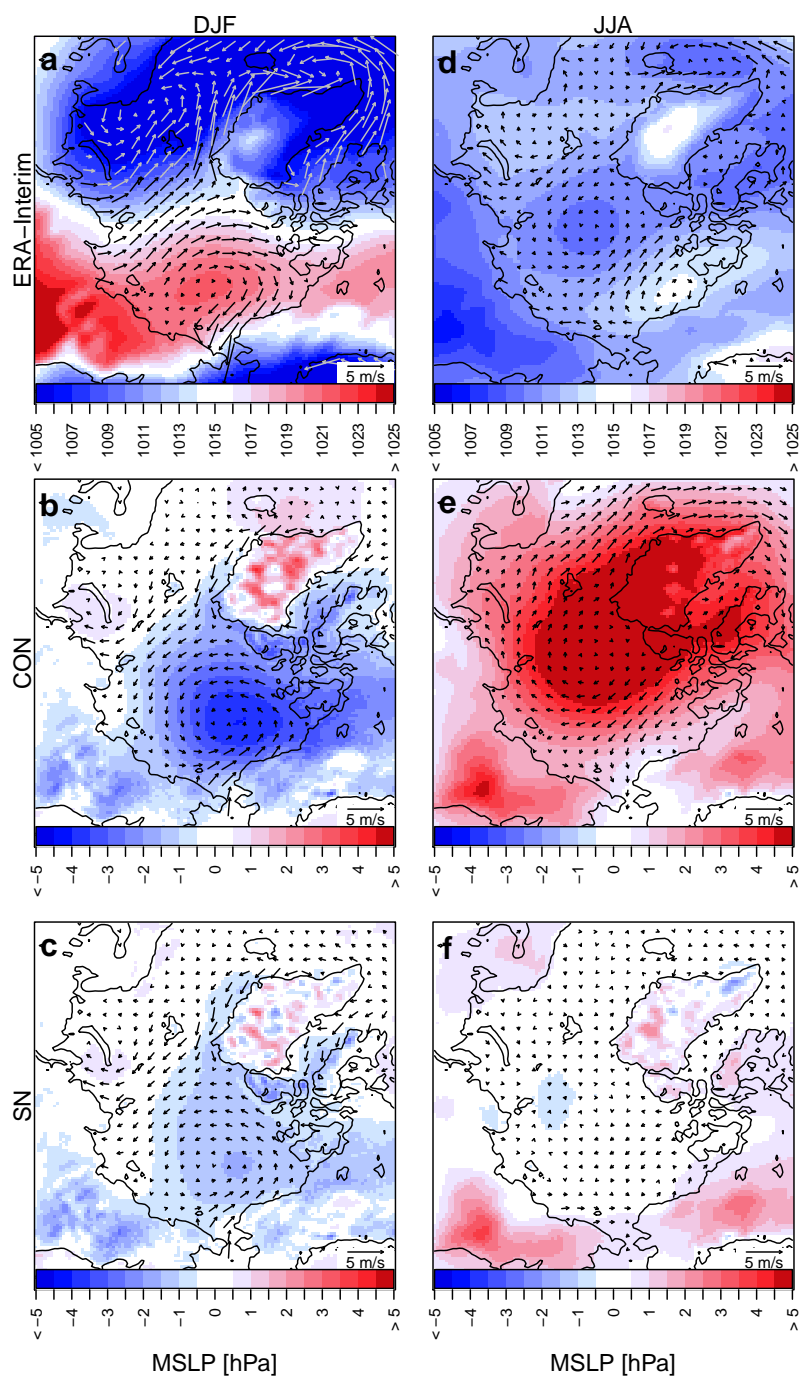

Fig. 3. MSLP of the ERA-Interim (top), and bias of CON (middle) and SN (bottom), with respect to ERA-Interim, for DJF (left) and JJA (right). Arrows indicate anomalies of wind speed and direction. Only winds over the ocean are shown for reasons of clarity.

cost increases dramatically. The nudging coefficient also has large impact on the RMSE (see Fig. 2c), with effects similar to increasing the nudging frequency, however, at no extra computational costs. Note that increasing the nudging coefficient and using a low nudging frequency could cause problems if the model drift from the driving fields is strong. With a nudging frequency of every $6 \mathrm{~h}$, it was found that the model produces oscillations of the nudged variables between the nudging steps. The domain average bias was investigated along with the RMSE with similar results (not shown).

In the additional tuning experiments for June (ii) and the complete year (iii), it was found that RCA produces a general strong temperature bias in the free troposphere (see Fig. 4), possibly due to a too-simplified radiation scheme. This bias is reduced by nudging of the winds, but an additional tempera- ture nudging is more efficient. Furthermore, it reduces inconsistencies between the variables at the nudging time steps. It was therefore decided to include also temperature among the nudged variables.

The final setup (UVTs1f1w800, hereafter referred to simply as SN) was decided upon as a compromise between computational cost and low RMSE. It uses a setup with a nudging strength of 0.1 , a frequency of once every hour, and a minimum wavelength defined by the driving model grid as about ten times the horizontal resolution, i.e. $10 \mathrm{~km} \times 80 \mathrm{~km}$ for ERA-Interim.

\section{Results of climatological simulations}

Surface winds directly affect the circulation of the ocean and sea ice (Rigor et al., 2002). Thus, regional biases of MSLP affect the sea ice distribution (Bitz et al., 2002; DeWeaver and Bitz, 2006; Chapman and Walsh, 2007). Here, we investigate the climatological-scale simulations of CON and SN for the time period 1980-2005. We focus the analysis on winter (DJF) and summer (JJA), because the biases are strongest for these periods. Generally, the biases in spring and autumn are weaker and intermediary of the winter and summer biases, with spring (autumn) more similar to those in summer (winter).

CON produces large MSLP biases and resulting surface wind biases (see Fig. $3 \mathrm{~b}$ and e). In winter, a negative bias of over $3 \mathrm{hPa}$ is centred over the Beaufort Sea. As a consequence, the winds from the Laptev Sea toward Greenland are reduced to close to half their strength. In summer, there is a strong positive bias of over $5 \mathrm{hPa}$ centred over the North Pole. This has consequences for the winds from the East Siberian Sea towards the Queen Elizabeth Islands, which are practically missing in CON. Winds from Greenland toward the Laptev Sea are strongly reduced, and anomalous winds toward the North Atlantic are formed in the RCM.

Coupled RCAO (RCA coupled with the Rossby Centre Ocean model, RCO; Döscher et al., 2002) simulations with an earlier version of RCA, albeit with similar biases, led to too-thick ice-cover along the Russian coastline (Döscher and Koenigk, 2012). This was partly due to regional MSLP biases connected to an anomalous ice flow towards the Siberian coast. Similar sea ice biases can be expected from the CON results.

Fig. $3 \mathrm{c}$ and $\mathrm{f}$ show the results for the $\mathrm{SN}$ simulation. Biases are strongly reduced, especially in summer where the bias over the ocean is less than $0.5 \mathrm{hPa}$, i.e. one-tenth of the bias in CON. In winter, the bias structure is retained from the CON simulation; however, it is reduced by more than a factor of two. Also biases over land are reduced in the nudged simulation, but not as strongly as for sea areas, perhaps due to the shorter distance to the lateral boundaries, i.e. less likelihood of having decoupled from the driving model. 

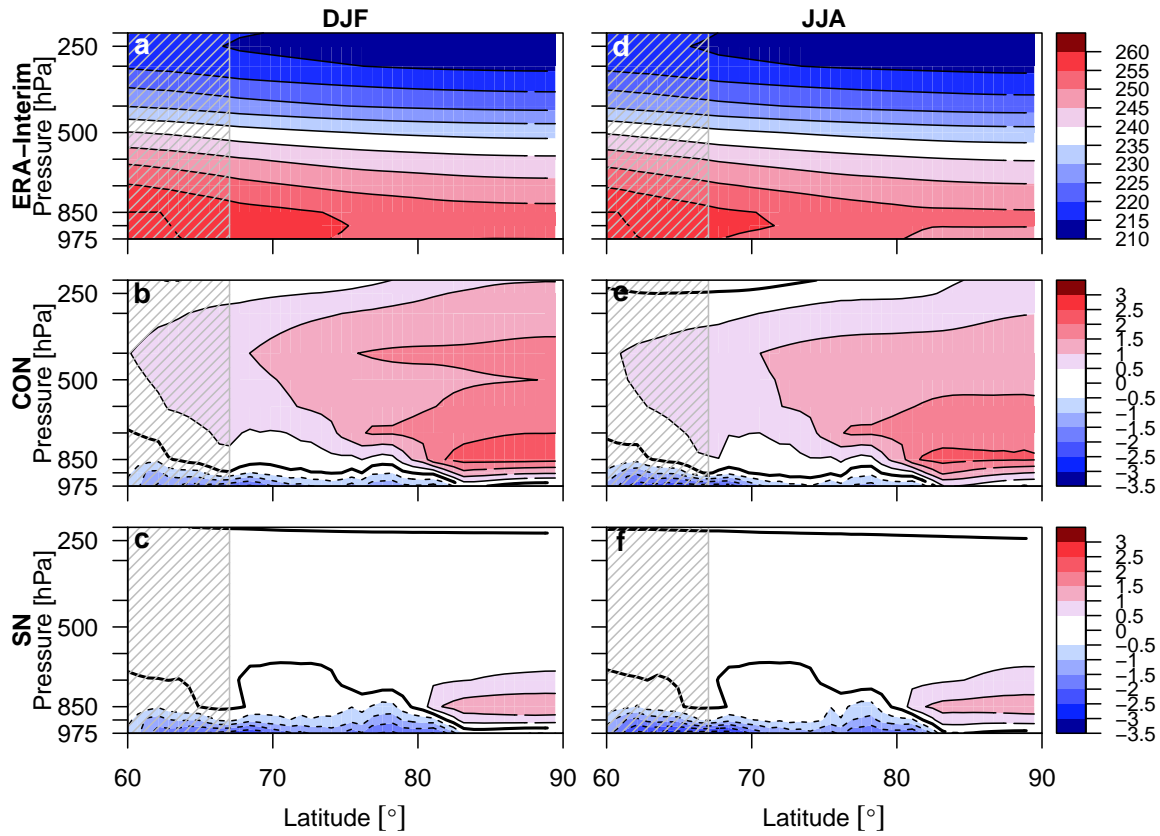

Fig. 4. Zonal mean temperature for ERA-Interim (top), and bias of CON (middle) and SN (bottom), with respect to ERA-Interim, for DJF (left) and JJA (right). The dashed regions indicate latitudes where no complete zonal means were possible (see Fig. 1), in which case also the corresponding ERA-Interim data were disregarded for the bias calculations. Note that only data from the interior domain are used; thus no relaxation to the driving data should be expected in the plots. Units are given in $\mathrm{K}$.
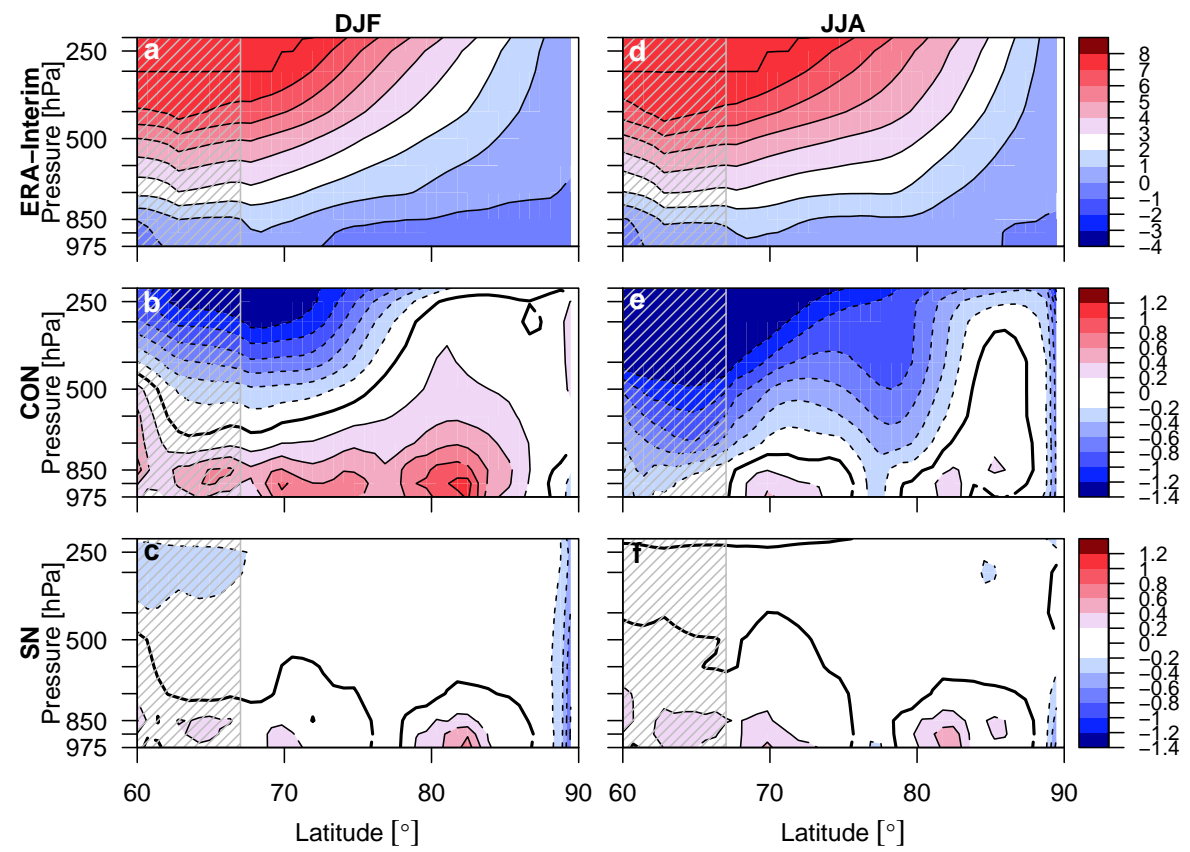

Fig. 5. Same as Fig. 4, but for zonal mean zonal winds, and units in $\mathrm{m} \mathrm{s}^{-1}$.

As discussed in Sect. 3, the CON simulation starts to deviate significantly from the driving data in the interior domain after only a few days. The reason is that the pressure systems crossing the domain follow slightly different paths and evolve differently in the RCM. It is thus reasonable to assume that the MSLP bias arises due to circulation biases.

In the free troposphere, $\mathrm{CON}$ has a general warm bias of the zonal mean temperature, with a peak of over $2 \mathrm{~K}$ over the 

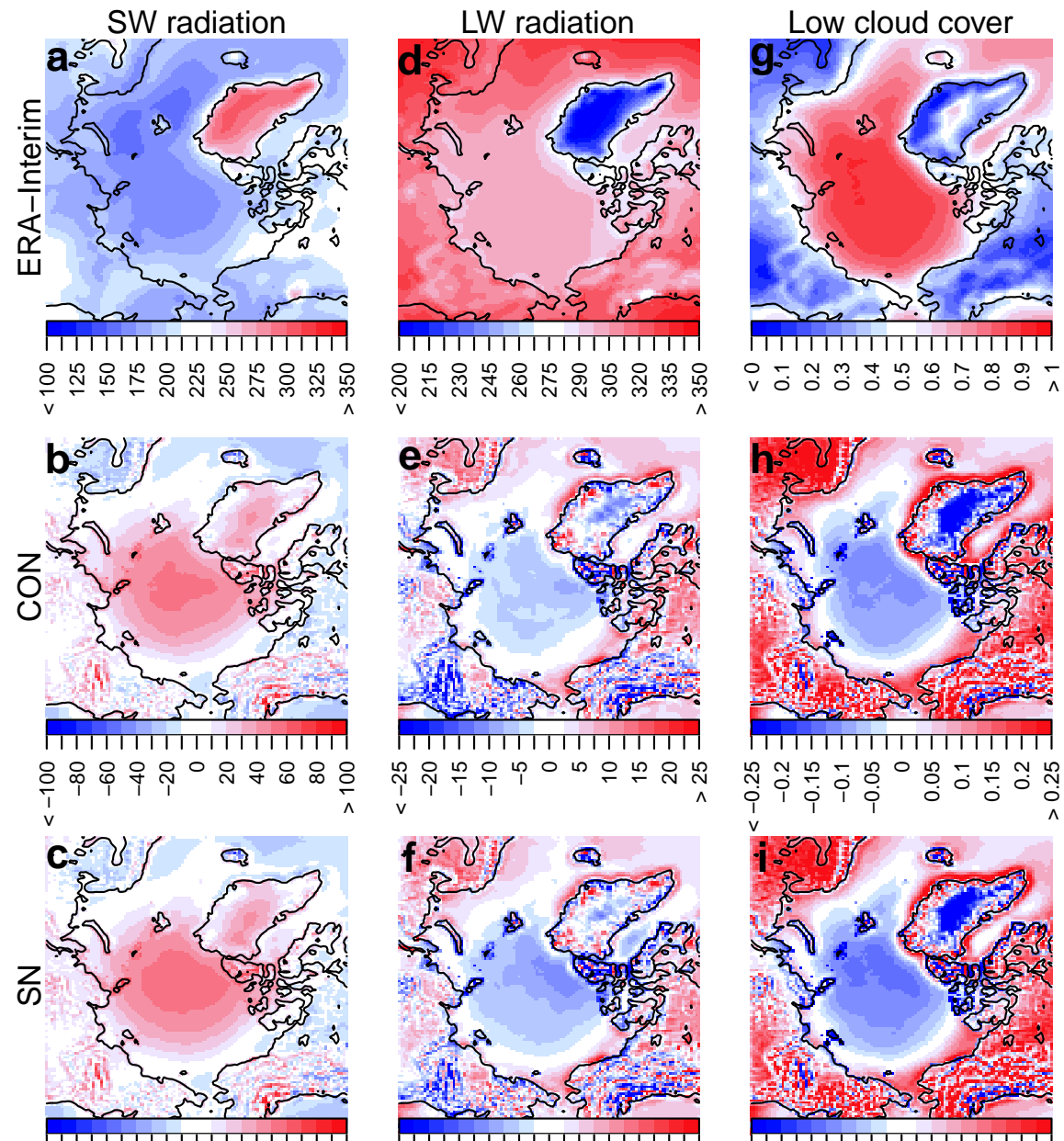

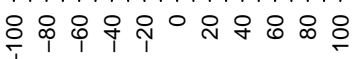

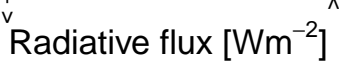

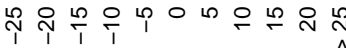

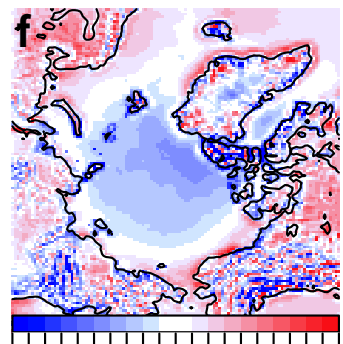

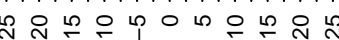

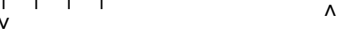

Radiative flux $\left[\mathrm{Wm}^{-2}\right]$

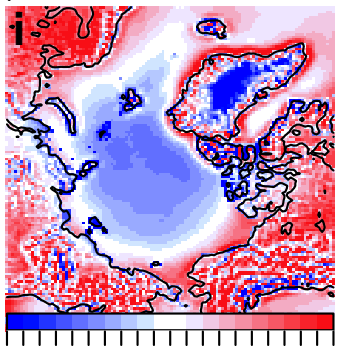

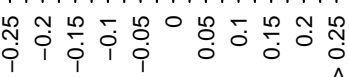

Fractional cloud cover [1]

Fig. 6. JJA downward surface shortwave (a-c) and longwave $(\mathbf{d}-\mathbf{f})$ radiation, as well as low cloud cover, defined as the fractional cloud cover below $650 \mathrm{hPa}(\mathrm{g}-\mathbf{i})$. The top row shows the ERA-Interim values, the middle row the bias of CON with respect to ERA-Interim, and likewise for $\mathrm{SN}$ in the bottom row.

North Pole at around $800 \mathrm{hPa}$ in winter (see Fig. 4b). The bias structure is similar in summer, although smaller in magnitude (see Fig. 4e). The zonal mean zonal winds are too strong in and above the boundary layer, and they extend farther up into the troposphere north of $80^{\circ} \mathrm{N}$ in winter (Fig. 5b). Further aloft, the zonal winds are underestimated, especially so approaching the polar jet stream. In summer, most of the tropospheric zonal winds are underestimated, with the exception of slight overestimations at most levels between $82^{\circ}$ and $87^{\circ} \mathrm{N}$ (see Fig. 5e). It seems like RCA is slowing down the zonal circulation significantly.

With spectral nudging, the biases in both temperature and zonal winds are strongly reduced in the middle and upper troposphere, where the nudging is strongest. At lower levels, the biases are still visible, with slightly weaker biases than those of the CON simulation north of $80^{\circ} \mathrm{N}$ and slightly stronger to the south. Note also that strong orographic features such as the mountains of Greenland are affecting the lowest terrain following pressure levels in this analysis, thus the ERAInterim and RCM results differ consequently at those levels due to differences in their orography fields.

Reducing the biases in the free troposphere, here through the spectral nudging method, gives positive results for the MSLP and surface circulation. Next we investigate whether there are adverse effects in other variables.

Figure 6 shows the incident shortwave $(\mathrm{a}-\mathrm{c})$ and longwave (d-f) radiation on the surface in summer. Observations of radiation are highly uncertain for the Arctic, and here we use ERA-Interim as a standard for comparison. CON produces more incident shortwave radiation and less longwave radiation at the surface, partly compensating for the former, compared to ERA-Interim. The main reason for the differences 


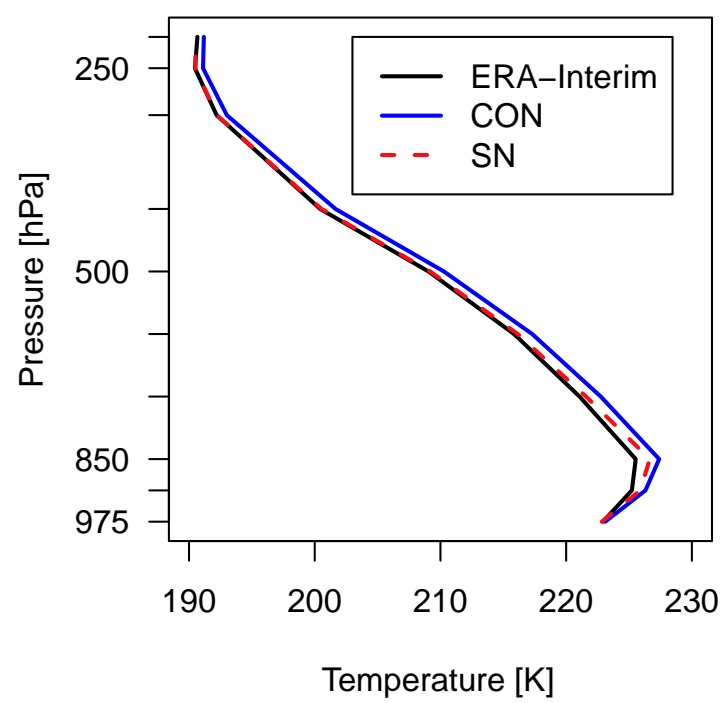

Fig. 7. Vertical temperature profiles for ERA-Interim (black), CON (blue) and SN (red) for the region north of $84^{\circ} \mathrm{N}$.

are less low-level clouds in CON (Fig. 6g-i), thus reducing the longwave radiation reflected back to the surface as well as the shortwave radiation reflected back to space. The differences increase when spectral nudging is applied, especially for the low clouds. A possible explanation is that the vertical temperature profile becomes steeper, i.e. more unstable, above the boundary layer north of about $84^{\circ} \mathrm{N}$ (see Fig. 7), which might affect cloud formation in the lower troposphere. However, a more in-depth analysis is needed to verify this hypothesis. Using a different vertical profile (see e.g. von Storch et al. (2000)) for the nudging strength could reduce this effect. The net surface shortwave and longwave fluxes show only very small differences between the simulations (not shown).

Also observations of two-metre temperature are uncertain in the Arctic region. In Fig. 8b-c and g-h, ERA-Interim is compared to the CRU and UDEL data sets. The results differ significantly for Greenland and the Queen Elizabeth Islands; however, there are similarities for other land regions. The seemingly robust features of the ERA-Interim biases consist of a cold bias along the Greenland west coast in winter and a general warm bias over eastern Russia and North America. The CON and SN (Fig. 8d-e and i-j) show similar biases in comparison to ERA-Interim. The RCA simulations are often colder over the continents, and warmer at Greenland coastal areas, thus reducing the biases of the ERA-Interim. SN is colder than CON over the Russian Arctic Ocean, but otherwise there are no large differences between the two simulations.

For precipitation, the differences between the observational data sets are largest over Greenland. ERA-Interim is generally too wet over Greenland, and too dry over the conti-
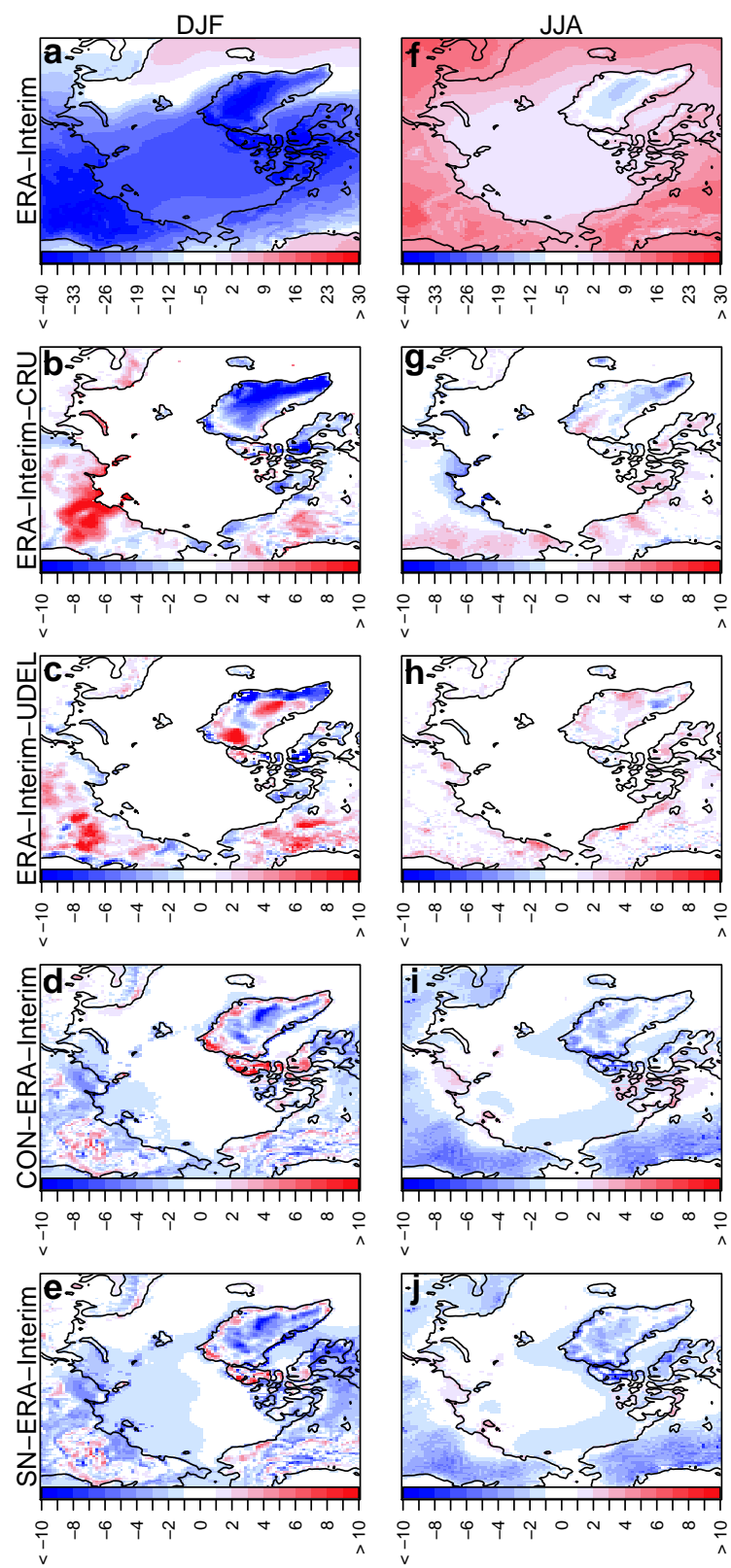

Fig. 8. Two-metre temperature of ERA-Interim (a, f), and its bias to CRU $(\mathbf{b}, \mathbf{g})$ and UDEL data $(\mathbf{c}, \mathbf{h})$. The bias of the CON $(\mathbf{d}, \mathbf{i})$ and $\mathrm{SN}(\mathbf{e}, \mathbf{j})$ are shown relative to ERA-Interim. Results are shown for DJF (left) and JJA (right). Units are given in $\mathrm{K}$.

nents (see Fig. 9b-c and g-h). RCA simulates more precipitation throughout the domain for both CON and SN (Fig. 9de and $\mathrm{i}-\mathrm{j}$ ), compared to observations, but less than ERAInterim. The main difference between the $\mathrm{CON}$ and $\mathrm{SN}$ simulations is decreased precipitation over the Barents and Greenland seas in winter and for the central Arctic and Greenland east coast in summer for SN. However, the great uncertainties in the observational data disqualify any ranking of the simulation results. 

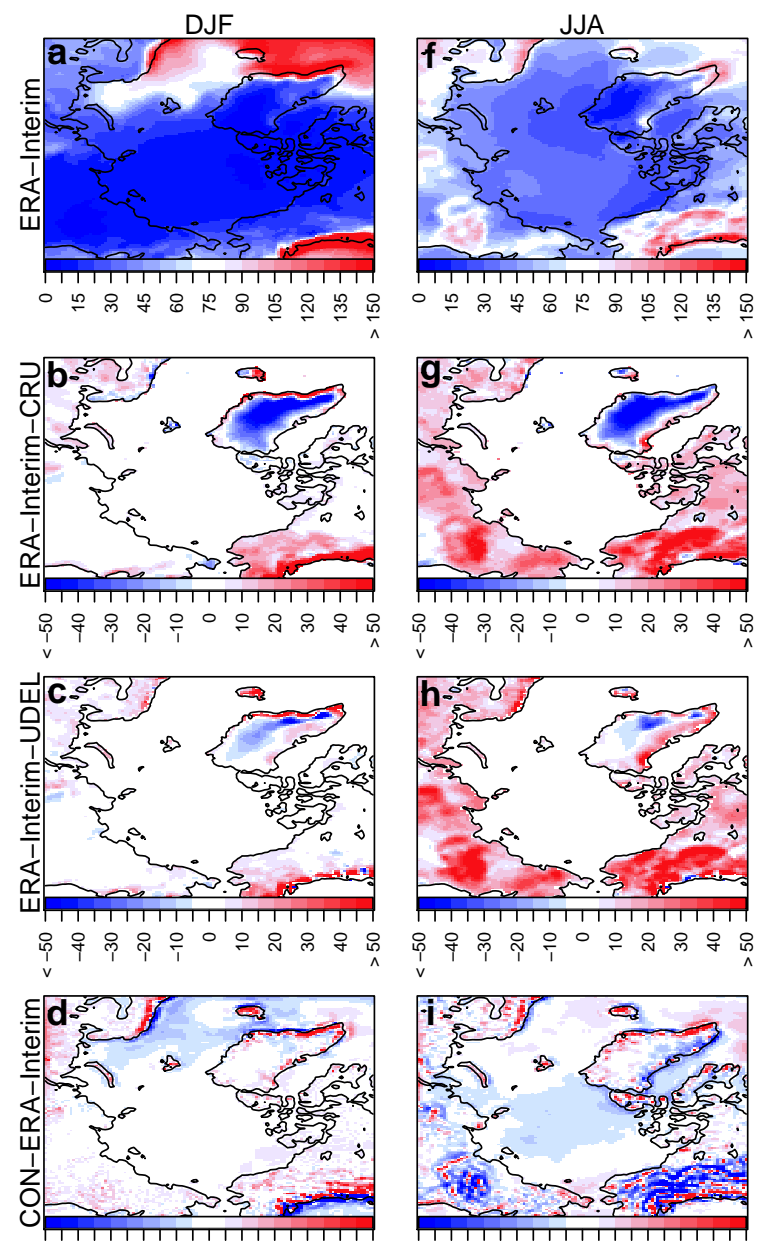

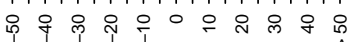

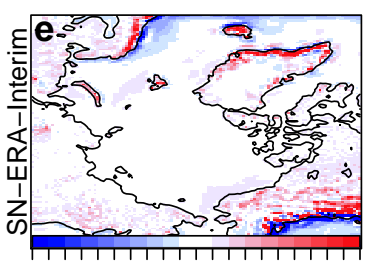

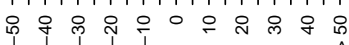
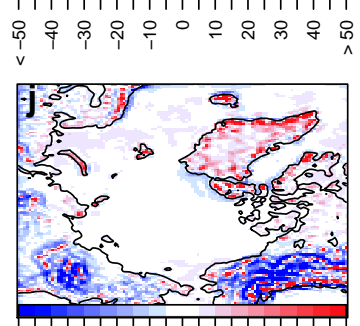

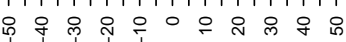

Fig. 9. Same as Fig. 8, but for precipitation in $\mathrm{mm} \mathrm{month}^{-1}$. Note that also GPCC data were included in the analysis, with results very similar to the UDEL shown in the figure, and are therefore not shown.

\section{Summary and conclusions}

The performance of the RCM RCA4 in re-analysis-driven simulations over the CORDEX-Arctic domain was investigated. Circulation biases were identified in the control simulation, and spectral nudging was implemented and applied in an effort to remedy the problems.
A set of experiments were carried out to tune the spectral nudging coefficients for optimal performance for both improved simulation results and computational efficiency. It was found that a calling frequency of at least one hour (every fourth time step) was necessary to avoid oscillations due to a strong drift between the RCA4 and driving model solutions. The shortest wavelength nudged influenced the results until a wavelength down to about $1000 \mathrm{~km}$, indicating that the deviations are in the longer wavelengths. The combination of an hourly calling frequency and a shortest wavelength of $800 \mathrm{~km}$, which fits with a multiple of the driving model resolution, allowed a weak nudging coefficient of 0.1 to be used.

The spectral nudging reduces biases throughout the free troposphere, where it was applied, with further effects at the surface. Bias in MSLP is much reduced in winter, and in summer there is practically no bias left over the Arctic Ocean after the nudging was applied. This MSLP bias reduction is also evident from the surface winds, which have much reduced bias. Especially the cross-Arctic Ocean winds are simulated better in the spectrally nudged simulation. These results are promising for future coupling of RCA with an ocean and sea ice model.

Two-metre temperature and precipitation are not significantly affected by the spectral nudging; however, increasing differences in ERA-Interim for both incident shortwave and longwave radiation at the surface were identified. The reason was found in a decrease in low-level cloud cover. A possible explanation for the increased cloud bias is that the spectrally nudged simulation changes the vertical temperature profile such that convective cloud formation is inhibited.

The main conclusion drawn is that RCA4 benefits mainly from spectral nudging in the Arctic domain, as it strongly reduces circulation bias. Interestingly, the improved circulation has very limited impact on surface variables, such as two-metre temperature and precipitation, and relatively little effect on radiation fluxes and clouds. Thus, spectral nudging has little effect on model deficiencies besides those directly affected by the nudged variables themselves. This implies that the RCA4 errors identified here are due to the physical parameterisations and the surface scheme used, rather than being consequences of the atmospheric circulation and temperature biases. Note that in a future coupled atmosphereocean model there may be large consequences due to stronger flux interactions between the adapting ocean and ice surfaces.

The spectral nudging method is useful to apply with reanalysis forcing at the lateral boundaries, as it compensates for the RCM's circulation deficiencies. However, the method relies on the driving model to handle the large-scale circulation well. For re-analysis data, this is a minor problem, but for free-running GCMs the large-scale circulation might not be well simulated. The RCM should then, ideally, improve on the GCM. However, this is generally not the case for the large-scale circulation in RCM simulations over the Arctic. Still, there is value in performing RCM simulations 
through increased near-surface details around complex orography, coast lines, etc., which the coupled system may benefit from. Complemented with standard simulations, the spectrally nudged simulations provide a measure for effects of circulation biases, and contribute to assessments of uncertainty in climate projections. There is ongoing work with analysing the effects of the method when applied to GCM downscalings directly, within the CORDEX framework. Further ongoing work involves coupling RCA4 to the RCO ocean model to perform scenario simulations with models from the CMIP5 ensemble.

Acknowledgements. This work was carried out at the Rossby Centre at the Swedish Meteorological and Hydrological Institute (SMHI) and made possible by the support of the ADSIMNOR project, funded by the Swedish research council FORMAS. We further acknowledge the provision and use of the observational data sets from CRU, GPCC and UDMA.

Edited by: J. Annan

\section{References}

Alexander, M., Bhatt, U., Walsh, J., Timlin, M., Miller, J., and Scott, J.: The atmospheric response to realistic Arctic sea ice anomalies in an AGCM during winter, J. Climate, 17, 890-905, doi:10.1175/1520-0442(2004)017<0890:TARTRA > 2.0.CO;2, 2004.

Alexandru, A., de Elía, R., Laprise, R., Šeparović, L., and Biner, S.: Sensitivity study of regional climate model simulations to largescale nudging parameters, Mon. Weather Rev., 137, 1666-1686, doi:10.1175/2008MWR2620.1, 2009.

Bitz, C., Fyfe, J., and Flato, G.: Sea ice response to wind forcing from AMIP models, J. Climate, 15, 522-536, doi:10.1175/15200442(2002)015<0522:SIRTWF > 2.0.CO;2, 2002.

Blanchard-Wrigglesworth, E., Armour, K. C., Bitz, C. M., and DeWeaver, E.: Persistence and Inherent Predictability of Arctic Sea Ice in a GCM Ensemble and Observations, J. Climate, 24, 231-250, doi:10.1175/2010JCLI3775.1, 2011.

Boerhout, J.: Reference HIRLAM scalability optimisation proposal, HIRLAM newsletter, 44, 22 pp., available at: http://www.hirlam. org/publications/NewsLetters/index.html, 2003.

Bromwich, D., Fogt, R., Hodges, K., and Walsh, J.: A tropospheric assessment of the ERA-40, NCEP, and JRA-25 global reanalyses in the polar regions, J. Geophys. Res., 112, 21 pp., doi:10.1029/2006JD007859, 2007.

Cassano, J., Higgins, M., and Seefeldt, M.: Performance of the Weather Research and Forecasting model for month-long pan-Arctic simulations, Mon. Weather Rev., 139, 3469-3488, doi:10.1175/MWR-D-10-05065.1, 2011.

Chapman, W. and Walsh, J.: Simulations of Arctic temperature and pressure by global coupled models, J. Climate, 20, 609-632, doi:10.1175/JCLI4026.1, 2007.

Christensen, J., Hewitson, B., Busuioc, A., Chen, A., Gao, X., Held, I., Jones, R., Kolli, R., Kwon, W.-T., Laprise, R., Rueda, V. M., Mearns, L., Menéndez, C., Räisänen, J., Rinke, A., Sarr, A., and Whetton, P.: Regional Climate Projections, in: Climate Change
2007: The Physical Science Basis. Contribution of Working Group I to the Fourth Assessment Report of the Intergovernmental Panel on Climate Change, chap. 11, 847-940, Cambridge University Press, Cambridge, United Kingdom and New York, NY, USA, 2007.

Dee, D. P., Uppala, S. M., Simmons, A. J., Berrisford, P., Poli, P., Kobayashi, S., Andrae, U., Balmaseda, M. A., Balsamo, G., Bauer, P., Bechtold, P., Beljaars, A. C. M., van de Berg, L., Bidlot, J., Bormann, N., Delsol, C., Dragani, R., Fuentes, M., Geer, A. J., Haimberger, L., Healy, S. B., Hersbach, H., Hólm, E. V., Isaksen, L., Kållberg, P., Köhler, M., Matricardi, M., McNally, A. P., Monge-Sanz, B. M., Morcrette, J.-J., Park, B.-K., Peubey, C., de Rosnay, P., Tavolato, C., Thépaut, J.-N., and Vitart, F.: The ERA-Interim reanalysis: configuration and performance of the data assimilation system, Q. J. Roy. Meteorol. Soc., 137, 553597, doi:10.1002/qj.828, 2011.

Denis, B., Côté, J., and Laprise, R.: Spectral Decomposition of Two-Dimensional Atmospheric Fields on LimitedArea Domains Using the Discrete Cosine Transform (DCT), Mon. Weather Rev., 130, 1812-1829, doi:10.1175/15200493(2002)130<1812:SDOTDA > 2.0.CO;2, 2002.

Deser, C., Tomas, R., Alexander, M., and Lawrence, D.: The Seasonal Atmospheric Response to Projected Arctic Sea Ice Loss in the Late Twenty-First Century, J. Climate, 23, 333-351, doi:10.1175/2009JCLI3053.1, 2010.

DeWeaver, E. and Bitz, C.: Atmospheric Circulation and Its Effect on Arctic Sea Ice in CCSM3 Simulations at Medium and High Resolution, J. Climate, 19, 2415-2436, doi:10.1175/JCLI3753.1, 2006.

Döscher, R. and Koenigk, T.: Arctic rapid sea ice loss events in regional coupled climate scenario experiments, Ocean Sci., 9, 217 248, doi:10.5194/os-9-217-2013, 2013.

Döscher, R., Willén, U., Jones, C., Rutgersson, A., Meier, H., Hansson, U., and Graham, L.: The development of the regional coupled ocean-atmosphere model RCAO, Boreal Environ. Res., 7, 183-192, 2002.

Haak, H., Jungclaus, J., Mikolajewicz, U., and Latif, M.: Formation and propagation of great salinity anomalies, Geophys. Res. Lett., 30, 1473, doi:10.1029/2003GL017065, 2003.

Häkkinen, S.: A simulation of thermohaline effects of a great salinity anomaly, J. Climate, 6, 1781-1795, doi:10.1175/15200442(1999)012<1781:ASOTEO>2.0.CO;2, 1999.

Koenigk, T., Mikolajewicz, U., Haak, H., and Jungclaus, J.: Arctic freshwater export in the 20th and 21st centuries, J. Geophys. Res., 112, G04S41, doi:10.1029/2006JG000274, 2007.

Koenigk, T., Mikolajewicz, U., Jungclaus, J., and Kroll, A.: Sea ice in the Barents Sea: seasonal to interannual variability and climate feedbacks in a global coupled model, Clim. Dynam., 32, 11191138, doi:10.1007/s00382-008-0450-2, 2009.

Laprise, R., Kornic, D., Rapaić, M., S̆eparović, L., Leduc, M., Nikiema, O., Luca, A., Diaconescu, E., Alexandru, A., LucasPicher, P., Elía, R., Caya, D., and Biner, S.: Considerations of Domain Size and Large-Scale Driving for Nested Regional Climate Models: Impact on Internal Variability and Ability at Developing Small-Scale Details, in: Climate Change, edited by: Berger, A., Mesinger, F., and Sijacki, D., Springer Vienna, doi:10.1007/9783-7091-0973-1_14, 2012.

Legates, D. and Willmott, C.: Mean seasonal and spatial variability in gaugecorrected, global precipitation, Int. J. Climatol., 10, 111- 
127, 1990.

Magnusdottir, G., Deser, C., and Saravanan, R.: The effects of North Atlantic SST and sea ice anomalies on the winter circulation in CCM3, Part 1: Main features and storm track characteristics of the response, J. Climate, 17, 857-876, doi:10.1175/15200442(2004)017<0857:TEONAS > 2.0.CO;2, 2004.

Miguez-Macho, G., Stenchikov, G. L., and Robock, A.: Spectral nudging to eliminate the effects of domain position and geometry in regional climate model simulations, J. Geophys. Res., 109, D13104, doi:10.1029/2003JD004495, 2004.

Mitchell, T. D. and Jones, P. D.: An improved method of constructing a database of monthly climate observations and associated high-resolution grids, Int. J. Climatol., 25, 693-712, doi:10.1002/joc.1181, 2005.

Nikulin, G., Jones, C., Giorgi, G., Asrar, G., Büchner, M., CerezoMota, R., Christensen, O., Déqué, M., Fernandez, J., Hänsler, A., van Meijgaard, E., Samuelsson, P., Sylla, M., and Sushama, L.: Precipitation Climatology in an Ensemble of CORDEXAfrica Regional Climate Simulations, J. Climate, 25, 6057-6078, doi:10.1175/JCLI-D-11-00375.1, 2012.

Richter-Menge, J. and Jeffries, M.: The Arctic, in "State of the Climate in 2010", B. Am. Meteorol. Soc., 92, S143-S160, doi:10.1175/1520-0477-92.6.S1, 2011.

Rigor, I., Wallace, J., and Colony, R.: Response of Sea Ice to the Arctic Oscillation, J. Climate, 15, 2648-2663, doi:10.1175/15200442(2002)015<2648:ROSITT>2.0.CO;2, 2002.

Rinke, A. and Dethloff, K.: On the sensitivity of a regional Arctic climate model to initial and boundary conditions, Clim. Res., 14, 101-113, doi:10.3354/cr014101, 2000.

Rudolf, B., Becker, A., Schneider, U., Meyer-Christoffer, A., and Ziese, M.: The new GPCC Full Data Reanalysis Version 5 providing high-quality gridded monthly precipitation data for the global land-surface is public available since December 2010, GPCC Status Report, December, 7 pp., 2010.
Samuelsson, P., Jones, C., Willén, U., Ullerstig, A., Gollvik, S., Hansson, U., Jansson, C., Kjällström, E., Nikulin, G., and Wyser, K.: The Rossby Centre regional climate model RCA3: model description and performance, Tellus, 63A, 4-23, doi:10.1111/j.1600-0870.2010.00478.x, 2011.

Šeparović, L., Elía, R., and Laprise, R.: Impact of spectral nudging and domain size in studies of RCM response to parameter modification, Clim. Dynam., 38, 1325-1343, doi:10.1007/s00382-0111072-7, 2012.

Symon, C., Arris, L., and Heal, B. (Eds.): Arctic climate impact assessment, Cambridge University Press, New York, NY, USA, 2005.

Undén, P., Rontu, L., Järvinen, H., Lynch, P., Calvo, J., Cats, G., Cuxart, J., Eerola, K., Fortelius, C., Garcia-Moya, J. A., Jones, C., Lenderlink, G., Mcdonald, A., Mcgrath, R., Navascues, B., Nielsen, N. W., Degaard, V., Rodriguez, E., Rummukainen, M., Sattler, K., Sass, B. H., Savijarvi, H., Schreur, B. W., Sigg, R., and The, H.: HIRLAM-5 Scientific Documentation, Tech. rep., Swedish Meteorological and Hydrological Institute, S-601 76 Norrköping, Sweden, 2002.

von Storch, H., Langenberg, H., and Feser, F.: A spectral nudging technique for dynamical downscaling purposes, Mon. Weather Rev., 128, 3664-3673, 2000.

Wyser, K., Jones, C., Du, P., Girard, E., Willén, U., Cassano, J., Christensen, J., Curry, J., Dethloff, K., Haugen, J.-E., Jacob, D., Køltzow, M., Laprise, R., Lynch, A., Pfeifer, S., Rinke, A., Serreze, M., Shaw, M., Tjernström, M., and Zagar, M.: An evaluation of Arctic cloud and radiation processes during the SHEBA year: simulation results from eight Arctic regional climate models, Clim. Dynam., 30, 203-223, doi:10.1007/s00382-007-0286$1,2008$. 